\title{
Correction to: Sodium nitroprusside enhances biomass and gymnemic acids production in cell suspension of Gymnema sylvestre (Retz.) R.Br. ex. Sm.
}

\author{
Ganesan Mahendran ${ }^{1}$. Deepak Kumar ${ }^{2}$. Sanjeet Kumar Verma ${ }^{1}$. Ashish Chandran ${ }^{1}$. Zafar Iqbal Warsi ${ }^{1}$. \\ Zakir Husain $^{1}$. Shama Afroz ${ }^{1}$. Prasant Kumar Rout ${ }^{2}$. Laiq Ur Rahman ${ }^{1}$
}

Published online: 5 July 2021

(c) The Author(s), under exclusive licence to Springer Nature B.V. 2021

\section{Correction to: \\ Plant Cell, Tissue and Organ Culture (PCTOC) \\ (2021) 146:161-170 \\ https://doi.org/10.1007/s11240-021-02058-7}

An incorrect concentration of Kn (Kinetin) was specified in the initial online publication. The original article has been corrected.

Publisher's Note Springer Nature remains neutral with regard to jurisdictional claims in published maps and institutional affiliations.
The original article can be found online at https://doi.org/10.1007/ s11240-021-02058-7.

Laiq Ur Rahman

1.rahman@cimap.res.in

Ganesan Mahendran saidhana30@gmail.com

Deepak Kumar deepakbharadwaj31@gmail.com

Sanjeet Kumar Verma sanjeet.kverma@cimap.res.in

Ashish Chandran chandranashish2607@gmail.com

ZZafar Iqbal Warsi zfriqba19@gmail.com
Zakir Husain

zakirhusain1993@gmail.com

Shama Afroz

shamaazmi90@gmail.com

Prasant Kumar Rout pk.rout@cimap.res.in

1 Plant Biotechnology Division, Central Institute of Medicinal and Aromatic Plants (CSIR-CIMAP), Lucknow 226015, India

2 Phytochemistry Division, CSIR-Central Institute of Medicinal and Aromatic Plants, Lucknow, Uttar Pradesh 226015, India 